\title{
Exercise in Patients with Essential Hypertension: Current Concepts
}

\author{
Eleni Gavriilaki*, Barbara Nikolaidou ${ }^{1}$ and Eugenia Gkaliagkousi ${ }^{1}$ \\ ${ }^{1} 2^{\text {nd }}$ Propedeutic Department of Internal Medicine, Aristotle University of Thessaloniki, Greece \\ ${ }^{2}$ Hippokration General Hospital, 49 Konstantinoupoleos Street, 54643 Thessaloniki, Greece
}

Essential hypertension represents a major public health problem leading to over 7 million deaths annually [1], as blood pressure (BP) levels are directly associated with vascular and overall mortality [2]. Accumulating data point towards a beneficial role of lifestyle changes, including increased physical activity, in promoting traditional cardiovascular risk factors' control (i.e. obesity, dyslipidemia, diabetes mellitus and hypertension). The importance of physical activity in essential hypertension is better understood taking into consideration that obesity, dyslipidemia and diabetes mellitus are common in hypertensive patients.

In 1953, Morris et al. [3] provided the first piece of evidence suggesting an association between fitness status and morbidity/ mortality with their study on drivers and conductors of London's doubledecker buses. Since then, well-designed epidemiological studies have confirmed the beneficial effects of adequate exercise on cardiovascular and all-cause mortality in healthy middle-aged [4-8] and older [911] men and women. Aerobic exercise exerts its beneficial effects on the cardiovascular system by promoting traditional cardiovascular risk factors' regulation (such as obesity, diabetes, dyslipidemia and hypertension). In terms of underlying pathophysiology, aerobic exercise seems to favorably regulate sympathetic nervous system (SNS) activity, inflammatory response, cardiac and vascular function (both arterial stiffness and endothelial dysfunction) [12].

Interestingly, the beneficial effects of exercise in cardiovascular health depend largely upon exercise type (strength or resistance vs. endurance exercise), frequency, duration and intensity. The reluctance towards resistance exercise tends to be replaced by an overwhelming number of studies and recent meta-analyses [13,14] showing its beneficial role, especially in combination with aerobic exercise analysis. However, additional studies are needed in order to further clarify its effects on cardiovascular risk management.

Despite the beneficial effects of regular physical activity on the cardiovascular system, acute physical activity has been implicated in triggering of acute cardiac events. In accordance with the aforementioned results, a recent meta-analysis of 14 studies showed a significant association of episodic physical and sexual activity with acute cardiac events (myocardial infarction / MI, sudden cardiac death / SCD and acute coronary syndrome) [15]. This association was observed even in individuals with high levels of regular physical activity, although the relative risk for MI and SCD reduced by $45 \%$ and $30 \%$ respectively, for each additional exercise session a week. Acute cardiac events are characterized by a circadian occurrence with a morning excess. This morning excess of acute cardiac events has been associated with the physiological morning rise of several neuroendocrine and hematologic factors [16]. The physiological morning response provides a pathophysiological link between acute cardiac events and dynamic exercise, through several common aspects (i.e. SNS activation, changes in coagulation and fibrinolysis and platelet activation).

In conclusion, cardiovascular effects of exercise in patients with essential hypertension have been thoroughly investigated by a number of experimental and clinical studies. In order to fully interpret this knowledge into clinical practice, we need to better understand the role of exercise intensity and duration on triggering or inhibiting this harmful pathophysiological cascade. Furthermore, of great importance is to elucidate optimal exercise training type, duration and intensity in special populations, such as older adults or patients with high cardiovascular risk.

\section{References}

1. Guilbert JJ (2003) The world health report 2002 - reducing risks, promoting healthy life. Educ Health (Abingdon) 16: 230

2. Lewington S, Clarke R, Qizilbash N, Peto R, Collins R; Prospective Studies Collaboration (2002) Age-specific relevance of usual blood pressure to vascular mortality: a meta-analysis of individual data for one million adults in 61 prospective studies. Lancet 360: 1903-1913.

3. Morris JN, Heady JA, Raffle PA, Roberts CG, Parks JW (1953) Coronary heartdisease and physical activity of work. Lancet 265: 1111-1120.

4. Blair SN, Kampert JB, Kohl HW 3rd, Barlow CE, Macera CA, et al. (1996) Influences of cardiorespiratory fitness and other precursors on cardiovascular disease and all-cause mortality in men and women. JAMA 276: 205-210.

5. Kokkinos P, Myers J, Kokkinos JP, Pittaras A, Narayan P, et al. (2008) Exercise capacity and mortality in black and white men. Circulation 117: 614-622.

6. Morris JN, Clayton DG, Everitt MG, Semmence AM, Burgess EH (1990) Exercise in leisure time: coronary attack and death rates. Br Heart J 63: 325334.

7. Paffenbarger RS Jr, Hyde RT, Wing AL, Lee IM, Jung DL, et al. (1993) The association of changes in physical-activity level and other lifestyle characteristics with mortality among men. N Engl J Med 328: 538-545

8. Wen CP, Wai JP, Tsai MK, Yang YC, Cheng TY, et al. (2011) Minimum amount of physical activity for reduced mortality and extended life expectancy: a prospective cohort study. Lancet 378: 1244-1253.

9. Kokkinos P, Myers J, Faselis C, Panagiotakos DB, Doumas M, et al. (2010) Exercise capacity and mortality in older men: a 20-year follow-up study. Circulation 122: 790-797.

10. Schnohr $P$, Scharling $H$, Jensen JS (2003) Changes in leisure-time physical activity and risk of death: an observational study of 7,000 men and women. Am J Epidemiol 158: 639-644.

11. Sui X, LaMonte MJ, Laditka JN, Hardin JW, Chase N, et al. (2007) Cardiorespiratory fitness and adiposity as mortality predictors in older adults. JAMA 298: 2507-2516.

12. Gielen S, Schuler G, Adams V (2010) Cardiovascular effects of exercise training: molecular mechanisms. Circulation 122: 1221-1238.

13. Umpierre D, Ribeiro PA, Kramer CK, Leitão CB, Zucatti AT, et al. (2011) Physical activity advice only or structured exercise training and association with $\mathrm{HbA} 1 \mathrm{c}$ levels in type 2 diabetes: a systematic review and meta-analysis. JAMA 305: 1790-1799.

14. Cornelissen VA, Fagard RH, Coeckelberghs E, Vanhees L (2011) Impact of resistance training on blood pressure and other cardiovascular risk factors: a meta-analysis of randomized, controlled trials. Hypertension 58: 950-958.

*Corresponding author: Eleni Gavriilaki, Hippokration General Hospital, 49 Konstantinoupoleos Street, 54643 Thessaloniki, Greece, Tel: +30 2310892 108; Fax: +302310 528 447; E-mail: elenicelli@yahoo.gr

Received April 12, 2013; Accepted May 18, 2013; Published May 20, 2013

Citation: Gavriilaki E, Nikolaidou B, Gkaliagkousi E (2013) Exercise in Patients with Essential Hypertension: Current Concepts. Gen Med (Los Angel) 1: 106. doi:10.4172/2327-5146.1000106

Copyright: (c 2013 Gavriilaki E, et al. This is an open-access article distributed under the terms of the Creative Commons Attribution License, which permits unrestricted use, distribution, and reproduction in any medium, provided the original author and source are credited. 